\title{
CONTROLE DO CAPITAL INTELECTUAL: UM MODELO APLICADO À GESTÃO DOS ATIVOS DO CONHECIMENTO
}

INTELLECTUAL CAPITAL CONTROL: A MODEL APPLIED TO THE MANAGEMENT OF KNOWLEDGE ASSETS

\section{CONTROL DE LA CAPITAL INTELECTUAL: UN MODELO APLICADO A LA GESTIÓN DE LOS ACTIVOS DE CONOCIMIENTO}

\author{
Ricardo Vinícius Dias Jordão \\ Mestre em Ciências Contábeis pela Universidade Federal de Minas Gerais - UFMG \\ Professor do Mestrado em Administração do Faculdades Pedro Leopoldo - FPL \\ E-mail: jordaoconsultor@yahoo.com.br (Brasil)

\section{Jorge Luís Pedreira Murteira Marques Casas Novas} \\ Doutor em Gestão pela Universidade de Évora, Portugal \\ Professor do Doutorado em Ciências Gerencias da Universidade de Évora, Portugal \\ E-mail: jlnovas@uevora.pt (Portugal)
}

\section{Antônio Artur de Souza}

Doutor em Management Science pala University of Lancaster, Inglaterrra

Professor da Escola de Ciência da Informação da Universidade Federal de Minas Gerais - UFMG

E-mail: antonioarturdesouza@gmail.com (Brasil)

\section{Jorge Tadeu de Ramos Neves}

Doutor em Génie Industriel Et Gestion de L'innovation Techno pelo École Centrale de Paris, França Professor da Escola de Ciência da Informação da Universidade Federal de Minas Gerais - UFMG E-mail: jitrneves@ufmg.br (Brasil) 
Controle do Capital Intelectual: Um Modelo Aplicado à Gestão dos Ativos do Conhecimento

\section{CONTROLE DO CAPITAL INTELECTUAL: UM MODELO APLICADO À GESTÃO DOS} ATIVOS DO CONHECIMENTO

\section{RESUMO}

A gestão do conhecimento (GC) e o capital intelectual (CI) têm sido temas de grande relevância no meio acadêmico e empresarial. A literatura sugere que há lacunas de pesquisa que precisam ser mais bem compreendidas. Tais lacunas advêm das dificuldades encontradas por pesquisadores e empresas em gerenciar, medir e controlar os ativos ditos intangíveis de uma organização. O objetivo da pesquisa descrita neste artigo é o de propor um modelo teórico-conceitual que apoie a construção de um sistema de controle do CI e a GC. Com este propósito, foi discutido o desenho do sistema de controle gerencial (SCG) e foram analisados os estudos anteriores que apoiaram a proposição do modelo em questão. Os resultados obtidos ampliam o conhecimento sobre o assunto e ajudam a preencher aquela lacuna de pesquisa, mostrando que: (1) um desenho adequado do SCG pode contribuir para a externalização de parte do conhecimento tácito, transformando-o em conhecimento explícito através de aculturação dos membros da empresa; (2) a cultura organizacional ajuda a sistematizar e disseminar o conhecimento na empresa; (3) o controle cultural pode ajudar a integrar os conhecimentos, gerenciá-lo e transformá-lo em CI; e (4) o SCG tanto pode colaborar no processo de socialização dos conhecimentos individuais como para a institucionalização do conhecimento coletivo com o objetivo de criar valor para as empresas.

Palavras-chave: Estratégia Competitiva; Gestão do Conhecimento; Capital Intelectual; Cultura Organizacional; Sistema de Controle Gerencial.

\section{INTELLECTUAL CAPITAL CONTROL: A MODEL APPLIED TO THE MANAGEMENT OF KNOWLEDGE ASSETS}

\section{ABSTRACT}

The knowledge management (KM) and intellectual capital (IC) have been topics of great relevance in academia and business. However, the literature suggests that there is a research gap that need to be better understood deriving from the difficulties encountered by researchers and companies in manage, measure and control the intangible assets. The purpose of this article is to propose a theoretical-conceptual model to support the development of a control system to IC and KM. Accordingly it is discussed the design of the management control system (MCS) and previous studies that supports the proposed model are analyzed. The study expands the understanding on the focal topic and helps to fill that research gap, showing that: (1) an adequate design of the MCS can contribute to the externalizing of part of the tacit knowledge, transforming it into explicit knowledge through acculturation of the members of the company; (2) the organizational culture helps to systematize and disseminate knowledge in the company; (3) the cultural control can help to integrate the knowledge, manage it and turn it into IC; and (4) the MCS can collaborate in the individual knowledge socialization process and in the collective knowledge institutionalization aiming to create value for companies.

Keywords: Competitive Strategy; Knowledge Management; Intellectual Capital; Organizational Culture; Management Control System. 
Ricardo Vinícius Dias Jordão, Jorge Luís Pedreira Murteira Marques Casas Novas, Antônio Artur de Souza \& Jorge Tadeu de Ramos Neves

\section{CONTROL DE LA CAPITAL INTELECTUAL: UN MODELO APLICADO A LA GESTIÓN DE LOS ACTIVOS DE CONOCIMIENTO}

\section{RESUMEN}

La gestión del conocimiento (KM) y el capital intelectual (CI) han sido temas de gran importancia en el mundo académico y empresarial. La literatura sugiere que existen lagunas en la investigación que necesitan ser mejor comprendidos. Estas deficiencias se deben a las dificultades que encuentran los investigadores y las empresas para gestionar, medir y controlar dichos activos intangibles de una organización. El objetivo de la investigación descrita en este documento es proponer un modelo teórico-conceptual para apoyar la construcción de un sistema de CI y CG control. Con este fin, hemos discutido el diseño del sistema de control de gestión (MCS) y se analizaron los estudios anteriores apoyaron la propuesta de que el modelo en cuestión. Los resultados amplían el conocimiento sobre el tema y ayudar a llenar ese vacío en la investigación al mostrar que: (1) diseño adecuado del SGC puede contribuir a la exteriorización del conocimiento tácito, transformándola en conocimiento explícito a través de la aculturación miembros de la empresa, (2) la cultura organizacional ayuda a sistematizar y difundir el conocimiento en la empresa, (3) control cultural puede ayudar a integrar los conocimientos, gestionarlo y convertirlo en CI, y (4) tanto el SCG pueden colaborar en el proceso de socialización del conocimiento individual en cuanto a la institucionalización de los conocimientos colectivos con el fin de crear valor para las empresas.

Palabras-clave: Estrategia Competitiva; Gestión del Conocimiento; Capital Intelectual; Cultura Organizacional; Sistema de Control de Gestión. 
Controle do Capital Intelectual: Um Modelo Aplicado à Gestão dos Ativos do Conhecimento

\section{INTRODUÇÃO}

A literatura tem mostrado uma variedade de estudos envolvendo a Gestão do Conhecimento (GC) e o Capital Intelectual (CI) (Edvinsson; Malone, 1997; Nonaka, 1991; Nonaka; Takeuchi, 1997; Lima; Beinichis, 2004; Choo; Alvarenga Neto, 2010; Lima; Beinichis, 2004; Perez; Famá, 2006; Alvarenga Neto, 2005; Novas et al., 2012; Jordão, 2011), sendo considerados temas de grande interesse nas comunidades acadêmicas e no ambiente empresarial (Kakabadse et al., 2003, Novas, 2008; Jordão; Colauto, 2012), em função da capacidade que os ativos do conhecimento têm de multiplicar o valor das corporações (Grant, 1996; Aboody; Lev, 1998; Luthy, 1998; Cassel; Hackl, 2000; Mouritsen et al., 2001; Ortiz, 2006; Luthy, 1998; Cassel; Hack1, 2000; Ortiz, 2006; Perez; Famá, 2006). Stewart (1998) define CI como o conjunto de conhecimentos e informações encontrados nas organizações, que agregam valor aos produtos e/ou serviços, mediante a aplicação da inteligência e não do capital monetário ao empreendimento, proporcionando-lhe vantagem competitiva. Esse autor explica que o CI subdivide-se em capital estrutural, humano e dos clientes.

Cada vez mais as empresas têm no CI seu maior elemento patrimonial (Joia, 2000; Silva, 2008), em razão da sua condição de ativo estratégico responsável pela geração e pela sustentação de vantagens competitivas (Kumar, 2005; Perez; Famá, 2006; Novas, 2008). Trata-se de ativos intangíveis que trazem contribuições substanciais para o valor econômico das empresas e no potencial de geração de lucros futuros das mesmas (Cassel; Hackl, 2000). Em contrapartida, Edvinsson e Malone (1997) ponderam que o não reconhecimento contábil do valor financeiro da parcela intangível do CI teria sido a causa de grandes discrepâncias existentes entre o valor de mercado das empresas e os valores declarados nas suas demonstrações financeiras (DF).

Em função das dificuldades em avaliar adequadamente o CI, Stewart (1998), em seu trabalho seminal, chegou a ponderar que os contadores não têm reconhecido o valor do elemento humano, das relações com os clientes e consumidores, dos sistemas e das estruturas DF das empresas. Não obstante, esforços para evidenciá-los de forma adequada vêm sendo propostos há mais de um século. No Brasil, o professor Eliseu Martins em sua tese de doutorado defendida no início de 1970 na USP já ponderava que alguns ativos intangíveis como o goodwill tem sido motivo de estudos, debates, leis, pesquisas, concordâncias e divergências desde há muitos anos. Martins (1972) afirma que as citações e referências a esse tipo de intangível datam de séculos atrás, sendo que o primeiro trabalho sistemático, tendo-o como tema central, data de 1891. Segundo Jordão (2008), o Goodwill consiste em um ativo de capital, sem existência física, sob controle e inseparável 
da entidade, que não possui usos alternativos e que é capaz de produzir (com alguma incerteza) benefícios econômicos futuros.

Mesmo que as pesquisas relativas aos ativos intangíveis tenham se iniciado há muitos anos, observam-se atualmente vários esforços dirigidos para (i) seu dimensionamento (Kumar, 2005; Jordão; Colauto, 2012), (ii) sua gestão (Edvinsson; Malone, 1997; Mouritsen et al., 2001; Choo; Alvarenga Neto, 2010) e (iii) seu controle (Barbosa; Gomes, 2002, Novas et al. 2012). Alguns autores tratam os intangíveis como um sinônimo do CI. Nesse sentido, Barbosa e Gomes (2002) esclarecem que os ativos intangíveis de uma empresa consistem em um conjunto formado por quatro fatores: (i) os conhecimentos acadêmico e tácito de seus funcionários; (ii) os seus processos facilitadores de transferência e aquisição de conhecimento; (iii) o seu relacionamento com os clientes, os fornecedores e o mercado de trabalho; e (iv) a sua capacitação em pesquisa e desenvolvimento. Barbosa e Gomes (2002:2) ainda afirmam que

a este conjunto de ativos/recursos costuma-se atribuir os nomes knowledge-based assets e capital intelectual, sendo que esta última forma parece estar ganhando mais espaço, tanto nos círculos acadêmicos e empresariais, quanto na mídia. Incorporado nos ativos/recursos intangíveis está o fator conhecimento, causa principal de sua intangibilidade e valor (grifo dos autores).

No que tange especificamente, ao estabelecimento de um sistema de controle gerencial (SCG) adequado sobre CI, Barbosa e Gomes (2002) explicam que esse controle deveria partir da hipótese de que os ativos e recursos básicos disponíveis para uma empresa - sejam eles pessoas, processos organizacionais e produtivos, tecnologias e insumos - somente seriam relevantes para a empresa se ela pudesse, de forma eficiente e eficaz, utilizar o conhecimento neles incorporado. Esses autores, contudo, não indicam a forma como esse controle sobre o CI deveria ser exercido. Tomando-se esse pressuposto como verdadeiro, ou seja, partindo-se da premissa de que é possível utilizar esse conhecimento com eficiência e eficácia, cabe então desenvolver modelos que expliquem e norteiem esse controle sobre o CI.

Assim, o objetivo da pesquisa descrita neste artigo é o de propor um modelo teóricoconceitual que apoie a construção de um sistema de controle do CI e a GC. Espera-se que tal modelo ajude a compreender melhor as relações existentes entre o SCG, a GC e o CI. Nesse intuito, discutiu-se o design do SCG e analisaram-se estudos prévios que indicassem alternativas que permitissem a proposição do modelo em questão.

A justificativa pesquisa ora descrita advém da melhoria do entendimento do efeito do SCG sobre a GC e sua relação com o CI e da evidenciação de uma maneira pela qual o SCG pode 
colaborar para a conversão de parte do conhecimento tácito em explícito. Uma grande parte do conhecimento não tem expressão: é conhecimento tácito. Stewart (1998) referia-se a esta questão designando-a de "problema de reconhecimento". O conhecimento tácito é um tipo de conhecimento difícil de explicar e de observar. Nonaka (1991) caracterizava-o como um tipo de conhecimento altamente pessoal, difícil de formalizar e, por essa razão, difícil de comunicar aos demais, ao contrário do que ocorre com o conhecimento explícito, que é formal e sistemático, podendo por isso ser comunicado e partilhado de forma expedita. Em certo sentido, o conhecimento tácito corresponde ao que usualmente se designa por know-how, mas contém também uma importante dimensão cognitiva: modelos mentais, crenças e perspectivas profundamente interiorizadas. $\mathrm{Na}$ opinião de Boiral (2002), o conhecimento tácito corresponde a um tipo de conhecimento crucial, ainda que pouco explorado. Em concreto, o autor destaca que apesar de o conhecimento tácito ser crescentemente considerado como uma dimensão essencial das "organizações que aprendem", escassos exemplos das suas manifestações, utilidade e papel nas organizações vêm sendo produzidos. De fato, apesar da sua natureza altamente empírica, o conhecimento tácito é visto demasiadamente como algo oculto, abstrato e mesmo inacessível. Com similitudes ao conceito de cultura organizacional, que tem muitos aspectos implícitos, o conhecimento tácito é difícil de gerir, uma vez que não pode ser reduzido a "variáveis" ou "coisas" susceptíveis de manuseamento e controle operacional por parte dos gestores, mas precisam ser pensadas e gerenciadas sob um prisma estratégico de forma similar a gestão de aspectos da cultura organizacional.

A relevância da pesquisa é ampliada pela originalidade do modelo proposto por não existir na literatura uma abordagem suficientemente estabelecida e testada que proporcione, ao mesmo tempo, (1) uma visão clara da relação entre o controle e o CI; e (2) uma maneira como o SCG possa proporcionar um incremento de valor na empresa por uma gestão mais eficiente e eficaz dos ativos do conhecimento formadores do CI. Finalmente, o problema analisado, além de preencher essas três lacunas teórico-conceituais, consta como recomendação de pesquisa de vários pesquisadores como Luthy (1998), Cassel e Hackl (2000), Kumar (2005), Ortiz (2006), Behr e Nascimento (2008) e Silva (2008).

O presente artigo está estruturado em 6 seções, incluindo esta introdução. Na seção 2, são descritos e discutidos os desafios e modelos inerentes ao controle e a gestão do conhecimento e do capital intelectual. Na seção 3, descreve-se a metodologia da pesquisa. Na seção 4, apresenta-se e descreve-se o modelo teórico de controle ora proposto $\mathrm{Na}$ seção 5, faz-se uma análise crítica do modelo proposto e de suas implicações para a gestão empresarial, $\mathrm{Na}$ seção 6, tecem-se as 
considerações finais acerca do modelo proposto e de seu potencial teórico e prático, seguidas das referências bibliográficas utilizadas.

\section{SISTEMA DE CONTROLE GERENCIAL, GESTÃO DO CONHECIMENTO E CAPITAL INTELECTUAL: DESAFIOS E MODELOS}

O novo contexto marcado pelo advento da globalização trouxe consigo mudanças tecnológicas, uma forte expansão na capacidade de processamento da informação e uma maior relevância de seu uso, visando o aumento da competitividade empresarial. Esse novo contexto tem como base central de competitividade a gestão dos ativos baseados no conhecimento. Contudo, de forma diferente dos recursos econômicos tradicionais e por apresentar uma forte dimensão tácita, o conhecimento como recurso econômico tem constantemente imposto certas dificuldades, em especial ao gerenciamento organizacional tradicional. Novas (2008) pondera que a importância do CI na atualidade tem sido amplamente reconhecida. Não sendo estranho, pois, todo interesse e esforço por parte de acadêmicos e organizações na dissecação da sua estrutura e na criação de modelos e ferramentas para a sua análise, compreensão, desenvolvimento, controle e avaliação. Ele explica que a evolução do SCG é naturalmente motivada pelas mudanças que ao longo dos tempos se produzem nos paradigmas organizacionais. Essa evolução cria as condições a uma resposta efetiva às questões de natureza teórica, técnica e prática que os novos paradigmas suscitam.

Nos anos 80, parcialmente em função da ausência de um paradigma dominante, observou-se uma crise conceitual, que envolvia o SCG, relativa ao uso de medidas inadequadas no processo de avaliação de desempenho. Argumentava-se que os sistemas de controle existentes não estavam sendo um instrumento efetivo que facilitasse e potencializasse o processo de tomada de decisão. Naquela época, Johnson e Kaplan (1987) discutiram a perda de relevância da informação advinda da contabilidade e dos sistemas de controle tradicionais. Esses autores argumentavam que essa perda de relevância vinha do fato de que grande parte das empresas da época se baseava, predominantemente, em um SCG focado em indicadores de caráter físico e financeiro.

Na década de 90, observou-se um crescente interesse dos estudiosos em compreender a estreita relação entre o contexto social, o funcionamento da empresa e o SCG. A partir desse período, constatou-se uma tendência de abandono de abordagens mecanicistas e o surgimento de uma perspectiva ampliada de controle com a incorporação de ideias oriundas de outras áreas do conhecimento tais como a sociologia, a psicologia, a antropologia e a filosofia na concepção do 
SCG. Nessa nova perspectiva, a empresa passou a ser abordada em um enfoque sistêmico, pelo qual as expectativas das pessoas e dos diferentes atores que interagem com ela precisam ser contempladas, na medida do possível. Atualmente, o SCG já é exercido congregando medidas quantitativas e qualitativas de desempenho de uma forma que complementa mecanismos formais de controle com mecanismos informais para estimular as pessoas a se comportarem de acordo com as expectativas empresariais (Gomes; Salas, 1997). O uso de mecanismos formais busca promover a melhoria da produtividade das pessoas e operações, dos resultados corporativos, do volume e da qualidade dos negócios. Os informais, por sua vez, baseiam-se na incorporação dos objetivos empresariais nos propósitos das pessoas, visando trazer ganhos às empresas pela interiorização, nos indivíduos, dos valores compartilhados pelo coletivo.

Novas (2008) destaca que o paradigma atual do SCG associa-a à gestão dos recursos organizacionais, consubstanciada no uso eficiente e na contribuição de tal sistema para o processo global de criação de valor, sendo o SCG fundamental na GC e no controle do CI. Esse autor considera que

\begin{abstract}
o CI é a expressão do valor de um tipo de recursos cujas propriedades e potencialidades os posicionam entre os principais elementos no processo de criação de valor organizacional. A gestão global dos referidos elementos representa, em consequência, uma nova responsabilidade organizacional. Pela sua própria natureza, o CI é heterogêneo: pode conter elementos fixos, como é o caso de uma patente, ou flexíveis, como as capacidades humanas; pode ser tanto o input como o output do processo de criação de valor. É específico, no sentido em que para a sua formação concorre um conjunto de elementos próprios da organização (conhecimento incorporado nas suas estruturas físicas, conhecimento não incorporado, relações entre equipes de trabalho, ou mesmo a cultura organizacional), mas suficientemente amplo para agregar todo um conjunto de relações com entidades externas, como os clientes ou a comunidade acadêmica. Tudo isto oferece dificuldades particulares e torna complexos os processos tendentes ao seu reconhecimento, gestão, medição e expressão, requerendo, em muitos casos, a confluência de saberes de diversos campos do conhecimento organizacional: estratégia, recursos humanos, marketing, ciências da informação, contabilidade e controle gerencial (Novas, 2008, p. 11)
\end{abstract}

Novas (2008) entende que os esforços para medir e controlar o CI são recentes, especialmente depois de 1995 - quando algumas abordagens de SCG se voltaram de forma mais sistematizada para a geração de valor nas organizações. Segundo Jordão (2009), entende-se como controle gerencial o sistema administrativo capaz de influenciar o comportamento dos membros da empresa e que consiste em verificar se todas as ações das pessoas e todos os processos estão sendo feitos conforme o planejado. Esse sistema tem o intuito de promover a eficácia organizacional e fazer com que a empresa siga os rumos previamente traçados pela alta direção e possa, assim, cumprir sua missão. Adicionalmente, esse autor ressalta que o SCG deveria ser um processo permanente, executado em todos os níveis, funções, projetos e atividades organizacionais com o 
objetivo de promover a congruência dos objetivos pessoais e empresariais. Através desse processo, as informações geradas serviriam como base para a tomada de decisões, para a formulação de políticas e estratégias e para a adequação de processos aos objetivos corporativos. O SCG deveria, ainda, proporcionar formas de intervenção organizacional que proporcionassem ajustes no sistema de gestão e a integração entre os diferentes níveis hierárquicos, atividades e unidades empresariais.

O SCG das corporações contemporâneas deveria incluir aos tradicionais indicadores econômicos, financeiros, de qualidade e de produtividade, outros. Alguns desses indicadores poderiam ser os relativos ao clima organizacional, à cultura, aos fatores ambientais, à posição competitiva das organizações, aos interesses dos stakeholders (Gomes; Salas, 1997) e, em especial, à satisfação dos clientes com os produtos, serviços e processos oferecidos pela companhia. Esse sistema deveria incorporar os aspectos que muitas empresas, baseadas no conhecimento, consideram importantes, como a avaliação de ativos intangíveis e gestão do CI, a melhoria dos processos internos e o aumento do aprendizado organizacional e do nível de satisfação dos consumidores.

$\mathrm{Na}$ academia, conforme esclarece Sveiby (1997), já foi apresentada uma miríade de propostas para a mensuração do conhecimento existente no CI. Porém, ainda não foi desenvolvido um método capaz de atender a todos os propósitos e necessidades (informacionais e gerenciais) das pessoas e empresas. Por essa razão, tal autor sugere que cada interessado selecione o método mais recomendável conforme o propósito, a situação e o tipo de público a que se dirige. Além disso, conforme se depreende de Cassel e Hackl (2000), muitos trabalhos negligenciam a importância de critérios objetivos de mensuração - critérios esses capazes de ensejar robustez estatística e comparabilidade entre resultados.

Para além destas linhas de pesquisa, diversos trabalhos empíricos têm sido desenvolvidos sobre os ativos intangíveis formadores do CI. Alguns têm, por exemplo, comparado a influência desses ativos sobre a cotação das empresas (Queiroz; Fuertes; Serrano, 2001) e abordado a influência de tais ativos no valor de mercado das empresas (Aboody; Lev, 1998; Barth; Clinch, 1998; Lev, 1999; Kristen; Gregory, 1999; Deng; Lev, 1999). Outros têm discutido a relevância dos ativos intangíveis para as avaliação e gestão de empresas (cf. Cañibano; García-Ayuso; Sánchez, 1999, que realizaram uma revisão da literatura a esse respeito). Outros têm também examinado as regras que se aplicam em diferentes países e organizações internacionais para contabilizar os ativos intangíveis (Stolowy; Jenny, 1999).

Luthy (1998) realizou uma investigação para identificar os meios de mensurar o CI, apontando aspectos incompreendidos quanto à sua avaliação - que pode ser feita por dois diferentes 
métodos. O primeiro seria avaliar cada item individualmente, de modo a conhecer o valor total do CI a partir de cada um de seus componentes. O segundo consistiria em mensurar o valor dos ativos intelectuais em termos financeiros em nível organizacional, sem fazer referência aos itens individuais - observar-se-ia, nesse caso, a contribuição do CI ao valor de mercado adicionado (MVA, do inglês Market Value Added) da empresa. As conclusões de Luthy (1998) indicaram que o processo de identificação, gerenciamento, avaliação e mensuração do CI tende a se tornar mais significativo à medida que as empresas se tornam cada vez mais dependentes do conhecimento.

Edvinsson e Malone (1997), Sveiby (1997, 1989) e Barbosa e Gomes (2002) abordam a questão do controle gerencial de ativos intangíveis (mesmo que de certo modo incipiente) a partir do reconhecimento da importância do conhecimento nesses ativos. Os autores dessa linha postulam que a mensuração desses ativos tende a ser mais eficiente e eficaz à medida que passam a se basear mais em indicadores de desempenho não financeiros do que nos tradicionais indicadores financeiros, tanto para a avaliação da real saúde da empresa como para a previsão de cenários futuros. A ideia central consiste na tentativa de aproximar a GC das necessidades da atual economia, ajudando as pessoas e as empresas a identificar e sistematizar os fatores geradores do CI. Os estudos com a abordagem supracitada se desenvolveram a partir de meados dos anos 1990, como uma resposta proativa a críticas levantadas por Johnson e Kaplan (1987). Um modelo desenvolvido com base nessa abordagem é o Balanced Scorecard (BSC), proposto como uma metodologia de avaliação de desempenho orientada a toda organização (Kaplan; Norton, 2001). Tal modelo veio auxiliar para que as empresas pudessem estabelecer ações que colaborassem para a criação de valor aos acionistas, para o atendimento das expectativas dos demais stakeholders, para a consecução das estratégias e, ainda, para a melhoria dos serviços, dos processos internos, do aprendizado e da inovação empresariais. Alguns autores incluem o BSC de Kaplan e Norton (2001) não como um modelo de capital intelectual, mas sim como um sistema de gestão estratégica, que inclui indicadores parciais de ativos intangíveis. A tabela de avaliação de desempenho balanceada defendida por eles consiste em quatro perspectivas: a financeira, a do cliente, a do aprendizado e crescimento e a dos processos internos do negócio. Estudos recentes, todavia, como os de Jordão e Novas (2013) demostraram que, com o tempo, o BSC veio incorporando aspectos próprios de um SCG.

Kaplan e Norton (2001) basearam-se em sua experiência profissional e num estudo com quase 300 executivos, para afirmar que a capacidade de executar a estratégia é, provavelmente, mais importante do que a qualidade da estratégia. Segundo esses autores, o cerne desse problema é que as estratégias estão mudando muito rapidamente, mas a forma de mensurá-las, não. A economia 
de hoje exige ferramentas que descrevam como gerenciar e medir os ativos intangíveis baseados no conhecimento e as estratégias criadoras de valor, construídas a partir desses ativos. Rossoni (2010) discutiu a relação do BSC com a GC em todas as quatro perspectivas observando que a GC complementa cada uma das quatro perspectivas propostas no BSC e que a perspectiva do aprendizado e crescimento no BSC funciona como uma alavanca para as demais perspectivas provocando uma reação em cadeia que terminaria afetando a estratégia e visão previamente estabelecidas.

Contudo, mesmo que o BSC pudesse oferecer um meio de gestão do conhecimento e controle do CI, ainda não há consenso entre os pesquisadores e profissionais sobre o modelo que seria mais adequado para mensuração do CI (Silva, 2008). Além disso, diversos modelos poderiam contribuir para uma adequada gestão dos ativos do conhecimento e do CI, dentre os quais, destacam-se como pioneiros no desenvolvimento da moderna abordagem do CI os trabalhos de Stewart (1998), o Navegador da Skandia (Edvinsson; Malone, 1997), o IC INDEX (Roos et al., 1997), o “Technology Brokser's CI Audit” (Brooking, 1996) e o “Intangible Asset Monitor" (Sveiby, 1997).

Além do trabalho de Stewart (1998), que divide o CI em capital estrutural, capital humano e capital de clientes, tem-se, segundo Queiroz et al. (2001), como um dos modelos mais referenciados na literatura, o Business Navigator, proposto por Edvinsson e Malone (1997) e aplicado pela primeira vez na companhia de seguros Skandia. Este modelo enfatiza a lógica do valor de mercado da empresa, que seria obtido pela soma do capital financeiro com o capital intelectual. Nesse modelo, o capital intelectual é desdobrado em capital humano e capital estrutural, o qual, por sua vez, é subdividido em capital cliente e capital organizacional.

O modelo proposto por Brooking (1996) também faz parte da linha voltada para o valor de mercado da empresa. O autor concebe o valor de mercado como a soma dos ativos corpóreos e do CI - consistindo em ativos de mercados, propriedade intelectual humana e ativos de infra-estrutura. Sveiby (1997) propõe o "Intangible Asset Monitor", que classifica os ativos intangíveis em três categorias: competição por recursos humanos, estrutura externa e estrutura interna. Finalmente, Ross (1996) e Ross et al. (1997) introduziram o conceito de índice de CI como uma medida que integra os vários componentes do capital intelectual (humano e estrutural) em uma única medida que resume o desempenho do capital intelectual.

Há ainda outros modelos, como os indicadores propostos por Tinoco (1996), utilizados para avaliação e controle dos investimentos feitos em capital humano. O referido autor observou que o SCG deve reconhecero valor das pessoas como recurso organizacional e estratégico, considerando 
Controle do Capital Intelectual: Um Modelo Aplicado à Gestão dos Ativos do Conhecimento

que informações relacionadas a essas pessoas são fundamentais para a sobrevivência e a continuidade das empresas no tempo. Além disso, identificou que o SCG avalia os custos incorridos por entidades para recrutar, selecionar, contratar, treinar e desenvolver os recursos humanos, como também as atividades de formação e conservação de tais recursos.

Recentemente, Novas et al. (2012) analisando as relações de complementariedade do SCG com o CI observaram as relações entre esse sistema e os elementos formadores do CI. O foco da análise recaiu na forma como o SCG contribui para o desenvolvimento do CI. Com base na evidência empírica que suporta a proposição de que o processo de criação de valor está fortemente associado ao nível de CI das empresas, o estudo também analisou o efeito do SCG sobre o desempenho através dos efeitos positivos desse sistema sobre o CI. As relações referidas foram consolidadas num modelo e testadas empiricamente através da técnica de modelagem de equações estruturais, baseando-se em dados recolhidos junto de 281 empresas portuguesas. Eles observaram que seis das nove hipóteses levantadas foram validadas, reafirmando a existência de efeitos diretos positivos entre o SCG e as dimensões capital humano e estrutural do CI. Os resultados permitiram confirmar também a validade conceitual interna do modelo circular para as relações entre as três dimensões do CI que integravam o modelo proposto. Por fim, os resultados revelaram a existência de um efeito direto e significativo entre o capital estrutural e o desempenho organizacional. Em termos globais, os resultados confirmam a validade do modelo conceptual proposto contribuindo assim para o aprofundamento do conhecimento sobre o papel do SCG no desenvolvimento do CI organizacional.

Ressalta-se, porém, que independente do modelo de SCG a ser adotado pela empresa para gestão do conhecimento e do CI, é essencial que os gestores estimulem os processos de criação, manutenção e desenvolvimento das informações e do conhecimento organizacional. Um dos problemas do estabelecimento de um modelo efetivo é explicado por Silva (2004), segundo o qual cada tipo de ativo intangível necessita de medidas de avaliação específicas. Entretanto, esse autor reconheceu que a avaliação de tais ativos, quando realizada adequadamente, proporciona à empresa uma imagem externa mais transparente para seus clientes, credores e acionistas, dentre outros.

Assim, conclui-se que a GC colabora para a competitividade da empresa e influencia no gerenciamento de suas atividades. Tal fato tem despertado a atenção de muitos pesquisadores, motivando o desenvolvimento de modelos que buscassem como capturá-lo e retê-lo no ambiente corporativo, como será apresentado nas seções 4 e 5. 


\section{METODOLOGIA DA PESQUISA}

A pesquisa descrita neste artigo baseia-se em um estudo de natureza qualitativa e de abordagem explanatória usando pesquisa bibliográfica (Cooper; Schindler, 2003; George; Bennett, 2005). Essa abordagem metodológica tem sido sugerida como suficientemente sensível para captar e analisar a complexidade inerente a um SCG (Gomes et al., 2000). De maneira mais específica, porém, pode-se dizer que a escolha de tal abordagem metodológica justificou-se pelo fato de ter sido considerado o método mais adequado para propor, por meio de uma discussão dialética, um modelo de controle do CI.

Segundo Cooper e Schindler (2003) os estudos explanatórios buscam investigar um problema em uma área de investigação pouco explorada e buscar, por meio de inferências, analisar as relações observadas entre os fenômenos pesquisados. No trabalho em tela, a investigação se pautou na compilação, escrutínio e inter-relação de resultados teórico-empíricos disponíveis na literatura. A análise desses trabalhos e inferências derivadas serviram aqui de base de argumentação e sustentação teórico-conceitual do modelo proposto.

De acordo com Richardson (1999), estudos qualitativos são aqueles que descrevem a complexidade de um problema e/ou analisam a interação entre as variáveis pesquisadas. A metodologia qualitativa é adequada quando se buscam maior riqueza de detalhes e compreensão do significado social. Já a escolha pela concepção de um modelo teórico-conceitual para analisar a relação do SCG com o CI é justificada pela escassez de empresas que adotem sistemas de controle que contemplem aspectos relativos à GC e ao CI (que permitam acesso aos dados) inviabilizando estudos de larga escala. Ademais, um estudo de caso único poderia limitar a capacidade de realização de inferências e contribuições para a construção de um modelo teórico - em linha com os objetivos desta pesquisa - mesmo considerando que todo estudo de caso é especial com muitos recursos contextualmente divergentes e que, por isso, merece ser investigado, em profundidade. Fica, todavia, registrada a limitação de uma correlação da teoria com a práxis empresarial neste momento. Tal limitação, no entanto, não é impeditiva para fazer relações e inferências neste caso específico, pois grande parte de tais inferências terão como base resultados publicados de estudos empíricos que promoverão maior robustez e consistência interna ao modelo. Se de um lado essa escassez implica a inviabilidade de estudos de larga escala, de outro ela também significa que estudos de casos seriam limitados por variáveis contextuais, o que limitaria a possibilidade de comparação entre diferentes realidades e a possibilidade de inferência e generalização necessária para a construção de um modelo abrangente. 
Controle do Capital Intelectual: Um Modelo Aplicado à Gestão dos Ativos do Conhecimento

Dentre as várias fontes de evidências existentes em um estudo de natureza qualitativa, priorizou-se o raciocínio dedutivo. Utilizou-se de construções mentais de conceitos, leis e teorias já estabelecidos como base de sustentação teórica da análise realizada. As variáveis extraídas da literatura que sustentarão o modelo ora proposto, consubstanciadas em premissas a serem analisadas são: (1) a cultura organizacional promove efeitos sobre a GC e o SCG; (2) o SCG colabora para a gestão do CI; (3) o SCG ajuda na implementação de estratégias e geração de valor; (4) o desenho do SCG do CI deve integrar variáveis quantitativas e qualitativas de desempenho para ser eficiente e eficaz; (5) o controle cultural facilita a disseminação e sistematização do conhecimento; e (6) o SCG colabora para a criação, armazenagem, divulgação e compartilhamento de conhecimentos tácitos e explícitos por meio da cultura organizacional.

Como fonte primária de evidências teóricas, utilizaram-se estudos sobre o SCG, cultura organizacional, GC e CI, avaliação e mensuração do CI, controle cultural, modelos de avaliação de desempenho, desenho do SCG, integração entre variáveis quantitativas e qualitativas em SCG, bem como modelos de GC e CI. Como será descrito na próxima seção, buscar-se-á descrever a concepção do modelo proposto na pesquisa - analisando as relações entre as variáveis de sustentação do mesmo.

\section{CONCEPÇÃO DO MODELO DE CONTROLE DO CAPITAL INTELECTUAL}

Segundo a Organização para a Cooperação e Desenvolvimento Econômico (OECD),a economia baseada no conhecimento é mercada por um ambiente competitivo intensivo em conhecimento, globalizada produtiva e financeiramente e liberalizada comercialmente (OECD, 2010). Nesse novo contexto, as mudanças tecnológicas, a forte expansão na capacidade de processamento das informações e o aumento na competitividade empresarial têm impactos significativos sobre o CI. Com efeito, o estabelecimento de um SCG efetivo sobre o CI deve ser vinculado à cultura organizacional e feito em conformidade com a estratégia da empresa, como já preconizado por Gomes e Salas (1997) ao explicarem a importância de tais variáveis sobre o desenho do SCG. Joia (2000) ressalta a estreita relação existente entre estratégia e o CI, além de ponderar que a estratégia empresarial oferece meios que facilitam a mensuração e gestão dos elementos formadores do CI. Barros (2003), por sua vez, explica que cultura é algo enraizado, um código construído ao longo do tempo e que orienta as atitudes em função dos valores das pessoas. Através da análise cultural das organizações, pode-se perceber o significado simbólico de muitas 
ações cotidianas já que as atividades das pessoas, geralmente, são configuradas pelos valores e pelos esquemas de significado compartilhados no interior dos diferentes grupos. Assim, na proposição do modelo, partiu-se da premissa de que a estratégia fornece a diretriz para a geração de valor consubstanciado no MVA. No modelo, usou-se a divisão de CI em estrutural, relacional e de clientes para discutir os desdobramentos dos efeitos do SCG sobre a GC e o CI. A base para o exercício do controle é a cultura organizacional - formando um controle cultural. Através desse controle, espera-se que as organizações tenham mais meios de visualizar a criação e sistematização do conhecimento e a gestão dos elementos formadores do CI - conforme será descrito nesta seção e na seguinte. Por conseguinte,

o CI exige uma nova abordagem de controle gerencial, na qual, além dos indicadores financeiros, são utilizados índices não financeiros. Portanto, do aspecto gerencial, o objetivo é desenvolver modelos de gestão que incluam a capitalização e possibilitem a avaliação dos ativos intangíveis (Silva, 2008: 32).

A concepção da estratégia busca coordenar as políticas corporativas para que se consiga atingir os resultados planejados a partir das competências e fraquezas da empresa, em função das oportunidades e ameaças existentes no ambiente organizacional (Andrews, 1971). O objetivo seria a criação e a manutenção de vantagens competitivas (Montgomery; Porter, 1998) e o estabelecimento de meios para explorar as capacidades fundamentais (core competencies) da corporação (Prahalad; Hamel, 1990). Segundo Anthony e Govindarajan (2002: 92), há diferentes formas de perceber e conceituar a estratégia. De um modo geral, porém, "há um consenso de que a estratégia descreve a direção geral em que uma organização planeja mover-se para atingir seus objetivos".

O planejamento estratégico pode compreender a dinâmica de geração de valor na empresa, mapeando as características únicas de seus ativos tangíveis e intangíveis (e das combinações existentes entre eles) para identificar as variáveis que exercem maior impacto no valor da empresa (Perez; Famá, 2006). Esse mapeamento deve enfocar em especial os ativos do conhecimento formadores do CI, uma vez que o CI surge do estreito relacionamento entre os ativos tangíveis e intangíveis e da forma como cada empresa utiliza os ativos do conhecimento.

Perez e Famá (2006) estudaram as características estratégicas do CI a fim de verificar se haveria uma correlação entre a maior presença desse capital e um desempenho econômico superior nas empresas. Eles demonstraram, estatisticamente, que o CI pode ser responsável por uma maior geração de valor aos acionistas. Esses autores concluíram que a crescente competição entre as empresas e o fenômeno de "comoditização" dos produtos e serviços tem elevado a importância estratégica dos ativos intangíveis formadores do CI, como fator de diferenciação entre empresas. 
Controle do Capital Intelectual: Um Modelo Aplicado à Gestão dos Ativos do Conhecimento

Segundo Nonaka e Takeuchi (1997), tem havido uma série de tentativas de sistematizar o conhecimento como um ativo da organização. Entretanto, as teorias e modelos existentes ainda não foram capazes de lidar de maneira suficientemente aceitável com o dilema da GC e da mensuração do CI, gerando diferentes correntes de pensamento. Lima e Beinichis (2004) explicam que, atualmente, são duas as principais tendências de propostas práticas para a GC: a primeira envolve aspectos organizacionais, como o fluxo de informações, a infraestrutura e o controle por meio de indicadores; a segunda refere-se ao aspecto humano, por meio da capacidade e potencial de criar e compartilhar conhecimentos através das pessoas.

Behr e Nascimento (2008) sugerem que a GC deveria ser percebida a partir do ambiente no qual se desenvolve e a partir dos efeitos que ela exerce e sofre desse ambiente. Esses autores ressaltam que uma adequada GC tem de diferenciar o conhecimento tácito do explícito, sendo o primeiro não documentado e quase não passível de ensino e difícil de ser externalizado e o segundo observável e documentável, esquemático, simples e passível de ensino. Em definição semelhante, Nonaka e Takeuchi (1997) apontam que o conhecimento explícito pode ser articulado na linguagem formal, em afirmações gramaticais, expressões matemáticas, especificações ou manuais. Já o conhecimento tácito é incorporado à experiência individual e envolve fatores intangíveis como, crenças, sistemas de valores, perspectivas e emoções.

Assim, no desenvolvimento da pesquisa ora descrita questionou-se se seria possível converter o conhecimento tácito em explícito e, sendo possível, de que maneira isso poderia ser feito? Um dos problemas apontados na literatura e que tem ganhado espaço nos círculos acadêmicos é o fato de que o conhecimento tácito é pessoal e, muitas vezes, as pessoas podem não estar dispostas a compartilhá-lo com outras pessoas e organizações. Nesse sentido, indo de encontro a essas ideias de Nonaka e Takeuchi (1997) sobre conhecimento táctico e explícito, buscou-se conceber o modelo apresentado na Figura 1 que será discutido a seguir. Esse modelo mostra como o controle cultural pode contribuir para o estabelecimento de um efetivo SCG sobre o CI. A premissa central ora defendida é que o controle cultural colabora para sistematizar parte dos conhecimentos formadores do CI por meio das atividades de socialização dos valores individuais e pela internalização dos valores coletivos inerentes à formação da cultura organizacional. 
Figura 1 - modelo de controle do capital intelectual mostrando os efeitos do controle cultural na gestão do conhecimento e desta na geração de valor (MVA).

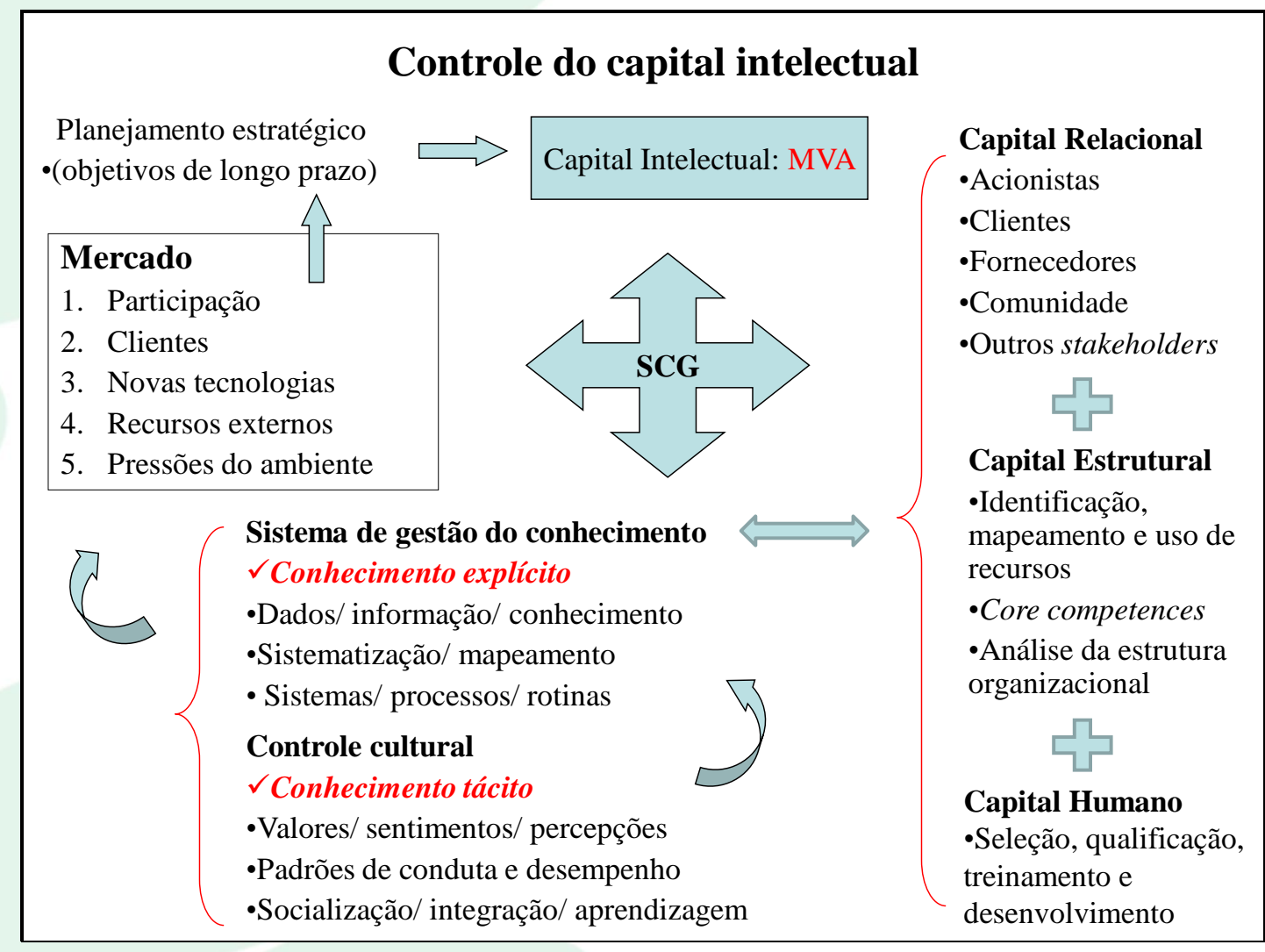

Fonte: Elaborado pelos autores.

A Figura 1 apresenta um modelo de controle do CI orientado pela estratégia empresarial, alinhando a GC e o controle cultural na tentativa de atender às expectativas do mercado e, assim, produzir CI - observado empiricamente pelo aumento de valor de mercado medido pelo MVA. A moderna teoria de finanças tem ressaltado que a melhor medida do sucesso empresarial em um mercado competitivo é a criação de valor (ou geração de riqueza) para os proprietários dessas empresas. Segundo Rappaport (1998), o valor é criado ao acionista somente quando as receitas de vendas superarem a todos os dispêndios incorridos, inclusive o custo de oportunidade do capital próprio.

A premissa central desse modelo é que a empresa torna o SCG mais eficiente e eficaz quando inclui as expectativas das pessoas no estabelecimento desse sistema gerando um controle cultural, como preconizado por Jordão (2009), tendo como base os pressupostos de Hofstede (1978). O controle cultural, quando estabelecido de forma consciente pela empresa ao lado de seu sistema de GC, ajuda no processo de conversão de parte do conhecimento tácito das pessoas em conhecimento explícito individual, coletivo e/ou organizacional. 
Controle do Capital Intelectual: Um Modelo Aplicado à Gestão dos Ativos do Conhecimento

O sistema de GC colabora para incremento do CI ao mesmo tempo em que se beneficia da estrutura da empresa estabelecida para incorporar o conhecimento oriundo do capital humano e relacional. Nesse modelo, o capital relacional não inclui somente o que a literatura denomina capital do cliente. Aqui se amplia o conceito defendido por Stewart (1998) do valor do relacionamento da empresa com seus clientes e fornecedores para o valor dos relacionamentos com todos stakeholders organizacionais. O modelo ora proposto se vale da cultura organizacional como instrumento de controle e como um fator catalisador das potencializadas de cada empresa para absorver parte dos conhecimentos tácitos de seus funcionários e transformá-los em ativos organizacionais.

Na visão de Behr e Nascimento (2008), o processo de conversão do conhecimento tácito em explícito embora complexo, poderia ser feito a partir da cultura organizacional e de atividades de socialização. A ideia é que a cultura organizacional ajuda na integração das pessoas às regras da empresa e facilita o compartilhamento de experiências. Já a socialização é apontada como uma forma de conversão de conhecimento tácito individual em tácito coletivo e, algumas vezes, de tácito em explícito. O argumento apresentado por esses autores é que a troca de experiências e habilidades, a partir dos modelos mentais das pessoas, estimula a absorção, a criação e a sistematização de novos e antigos conhecimentos por elas. As ideias desses autores, embora de certo modo polêmicas - por não aprofundarem na forma como o conhecimento tácito, que por natureza é difícil de ser ensinado, seria convertido em explícito - vêm ao encontro da necessidade de se estabelecer um SCG adequado sobre o CI, já que ajudam a trazer à luz um caminho a partir do qual essa ideia poderia ser desenvolvida: a cultura organizacional.

Talvez por isso as organizações tenham aumentado a utilização de controles derivados da cultura empresarial, porque ela é um dos principais fatores responsáveis pela orientação do comportamento das pessoas. Diferentemente do controle burocrático, legal e racional, o controle cultural é caracterizado por forças internas, tais como obrigação social, vocabulário-padrão utilizado, compartilhamento da história organizacional e senso de pertencer à organização e compreender seu papel nela (Steil; Sanches, 1998). No contexto desta discussão, faz-se relevante ressaltar a importância da cultura organizacional para facilitar o controle do CI. O SCG, nesse caso, pode facilitar o processo de negociação dos objetivos individuais e coletivos na concepção do orçamento empresarial, de modo a proporcionar os melhores resultados para a organização. Isso se dá a partir da consideração de uma cultura organizacional que estimule a incorporação de parte dos objetivos individuais no orçamento empresarial, gerando com isso um maior comprometimento com os resultados pactuados. Segundo Rodrigues e Barros (2001), a cultura organizacional é composta pelo conjunto de valores compartilhados pelo coletivo e é responsável pelo significado simbólico de 
muitas ações cotidianas das pessoas no âmbito das empresas. Ao analisar a cultura organizacional no âmbito das empresas, a constatação de tais autoras foi que as empresas sofrem influências das diferenças culturais existentes entre países e regiões geográficas nas quais estão instaladas.

\section{ANÁLISE CRÍTICA E DISCUSSÃO DO MODELO}

Embora as principais variáveis apresentadas no modelo ora proposto já tenham sido discutidas em outras pesquisas sobre a GC e o CI, como (i) Stewart (1998) que divide o CI em seus três elementos constitutivos; (ii) Nonaka e Takeuchi (1997), que descrevem o processo de conversão de conhecimento; (iii) Hofstede (1978), que demonstra a importância central da cultura nas práticas gerenciais; (iv) Behr e Nascimento (2008), que ressaltam que o processo de conversão do conhecimento tácito em explícito poderia ser feito a partir da cultura organizacional e de atividades de socialização; (v) Jordão (2009), que demonstrou que o SCG influencia e é influenciado pela cultura formando um controle cultural; (vi) Novas (2008) que destaca a necessidade de uma confluência de saberes do conhecimento organizacional para formação de um SCG que colabore efetivamente para a gestão, medição e expressão do CI; e (vii) Novas et al, (2012), que demonstram estatisticamente as relações entre o SCG e CI, bem como a interdependência entre as três dimensões constituintes do CI no processo de geração de valor. No entanto, o entendimento das relações entre todas variáveis que originaram esse modelo é ainda incipiente na literatura. Ademais, não há um modelo teórico-conceitual que os autores conheçam que vincule, especialmente, as formas de converter parte do conhecimento das pessoas em um ativo das empresas - o que aqui é feito a partir da criação de uma cultura que vincule a inclusão das pessoas em uma estratégia de constante inovação, estimulando que as pessoas façam parte dos processos e possam se beneficiar dos ganhos advindos com essa abordagem.

O maior problema que surge com tal abordagem é que, sendo o conhecimento um ativo individual, as pessoas podem não estar dispostas a disponibilizar o que sabem (i) seja por medo de perder seus empregos, (ii) pela falta de estímulos adequados ou ainda (iii) em função das dificuldades inerentes ao processo de retenção, armazenagem, distribuição e compartilhamento desses conhecimentos. Nesse sentido, vale ressaltar que nem todas as organizações, empresariais ou não, terão os meios suficientes para estimular as pessoas a criar, desenvolver e compartilhar seus conhecimentos nessas e para essas organizações. 
Controle do Capital Intelectual: Um Modelo Aplicado à Gestão dos Ativos do Conhecimento

Todavia, faz-se necessário destacar também o que muitas empresas baseadas no conhecimento já têm obtido sucesso com ações realizadas nesse sentido. Alguns casos, como das empresas 3M, Disney, Hewlett Packard, IBM, Johnson \& Johnson, Merck, Procter \& Gamble, General Electric e Sony, têm sido destacados na literatura e no mercado. Essas empresas são reconhecidas pela excelência em suas práticas gerenciais que produzem, armazenam, distribuem e partilham conhecimentos internamente - o que se materializa em novos produtos, serviços e processos e se consubstancia na geração de valor de mercado, como evidenciado por Collins e Porras (1994). Esses autores demonstraram, com significância estatística, que tais empresas, consideradas por eles como "visionárias", não apenas geraram retornos seis vezes maiores - sob o prisma do MVA - considerando as empresas de comparação (que também são empresas de excelência em seus mercados) e mais de quinze vezes superiores à média dos fundos de mercado geral. Além disso, evidenciaram que essas empresas sobreviveram, cresceram e se desenvolveram de forma a transformar suas perspectivas de negócios e uma parcela significativa do mundo em que vivemos ao longo de sua existência.

A ideia defendida pelos autores de comparar empresas de ponta entre si, destacando as que se superaram tornando-se líderes no que fazem e referências no mercado, revelou que as empresas "visionárias" buscavam usar sua cultura alinhada aos clássicos mecanismos de recompensas e outras ferramentas de controle para preservar a essência de seus negócios e prosperar em uma espiral de inovação e conhecimento. Foram dados inúmeros exemplos da criação, uso e compartilhamento das informações e conhecimentos como a criação de uma cola que não cola pela 3M em 1968. Em um primeiro momento, a cola não apresentou qualquer serventia, mas em 1977, outra equipe da empresa descobriu um uso singular para aquela descoberta. Desde então, vários novos produtos foram desenvolvidos como os blocos post-it ${ }^{\circledR}$ - que revolucionaram seus mercados, gerando atrás de si não somente novas linhas de produtos, mas também uma divisão inteira de negócios.

Segundo a empresa 3M trata-se do "mais famoso e inovador bloco de recados do mundo". Quando foi lançado, em 1980, obteve um sucesso tão grande e imediato que a 3M recebeu mensagens dos principais CEOs listados no ranking da Fortune 500, como o lendário presidente da Ford, Lee Iacocca, afirmando quanto havia gostado desse lançamento. Nos 30 anos seguintes, a marca Post-it ${ }^{\circ}$ cresceu e gerou toda uma família de novos produtos. Nos dias de hoje, existem mais de 1.000 produtos com a marca Post-it ${ }$, em grande número de formatos, tamanhos e cores, vendidos em mais de 100 países (3M, 2012). Todavia, mais do que ressaltar um ou outro produto de cada empresa, Collins e Porras (1994) evidenciam que tais empresas foram capazes de fazer isso ao 
longo de décadas (ou séculos) sem perder sua identidade, além de formar sucessores internamente, sem nunca achar que o ponto em que chegaram já era o bastante. O que levou a questionar: qual desenho de SCG seria necessário para estimular processos de inovação e geração de conhecimentos similares a esses? A partir de tal questionamento, buscou-se a analisar o papel desempenhado pelo controle cultural no processo de aprendizagem organizacional.

Uma possível resposta encontrada na literatura fora apresentada por Hofstede (1978), que já havia se manifestado contrariamente a uma visão mecanicista da administração que estimulava a divisão do trabalho entre unidades controladas e controladoras. Como alternativa esse autor propôs um modelo em que o SCG deveria ser baseado em grupos quase autônomos direcionados ao autocontrole e que se ajustasse às diferentes necessidades empresariais para promover a plena realização das mesmas. Esse modelo passou a valorizar (1) os objetivos das pessoas, com possibilidade de coalizão com os propósitos empresariais; (2) a negociação, como diretriz do sistema; e (3) a correção dos erros ao longo do processo. Hofstede (1978) argumentava que o ajuste por feedback é feito com resultados finalizados e os erros cometidos produziram "custos afundados" ( sunk costs) - que já não mais podem ser recuperados.

A visão desse autor partiu da premissa que o desenho do SCG deveria se basear em variáveis políticas, nos valores culturais, na capacidade de julgamento das pessoas e na negociação. Assim, um só controle poderia ter diversos desdobramentos diante de cada situação e ser mais flexível. Segundo essa premissa, cada empresa poderia conceber o desenho de seu SCG de acordo com seus objetivos, valores e formas de lidar com as mudanças no ambiente de negócios.

O desenho compreende a estrutura do controle e o processo de controle. A estrutura de controle deve considerar os indicadores (variáveis-chave) que possibilitarão o controle de cada unidade, a mensuração de sua atuação e o sistema de informação que permita o acompanhamento periódico da evolução dos indicadores identificados. Já o processo de controle representa o planejamento, a avaliação do resultado e as decisões corretivas (Mendes et al., 2002: 4).

Se bem desenhado, o próprio SCG pode ser utilizado como sistema de informações, porque os sistemas de controle são, para os gestores, uma ferramenta que pode lhes fornecer dados e informações sobre os níveis de desempenho planejado e realizado. Com essas informações, os gestores podem fazer comparações em bases objetivas, em todas as etapas dos processos de gestão e em todas as áreas, atividades e funções empresariais (Catelli, 1999). A justificativa para usar o SGC visando proporcionar melhores informações consiste na necessidade de sistematizar o conhecimento e melhorar o processo decisório nas empresas. Portanto, embora cada vez mais a tecnologia 
contribua para que mais informações possam ser disponibilizadas aos usuários com menores custos, o foco na concepção do desenho do SCG deve recair prioritariamente sobre uma melhoria da competitividade e geração de valor. Nesse sentido, o desenho do SCG ora proposto busca facilitar a GC e estimular a criação de um ambiente em que a cultura existente se volte para a geração de CI. Assim o SCG, além de potencializar o processo de tomada de decisão e estimular as pessoas no alcance dos objetivos, seria um dos elos-chave no alcance das estratégias e no cumprimento da missão empresarial: que é a razão da existência corporativa.

Anthony e Govindarajan (2002), embora de uma corrente teórica diferente daquela adotada por Hofstede (1978), concordam que o controle nas empresas não ocorre primordialmente em consequência de ações externas. Anthony e Govindarajan (2002) afirmam que muitas pessoas atuam em função do autocontrole porque seus próprios julgamentos lhes indicam as ações mais apropriadas e não porque receberam instruções específicas de seus superiores.

Estudos empíricos têm mostrado que a cultura organizacional produz efeitos sobre as práticas de gestão (Hofstede, 1982; Barros, 2003) e sobre o desenho e a utilização do SCG (Calori et al., 1994; Larsson; Lubatkin, 2001; Jordão, 2009; Granlund, 2003; Jordão; Souza, 2011). A inclusão de cultura organizacional no rol de indicadores qualitativos poderia possibilitar a manutenção e melhoria do nível de comprometimento organizacional, como demonstrado por Steil e Sanches (1998). Essas duas autoras realizaram um estudo em que investigaram o comprometimento organizacional como uma ferramenta de controle. Elas analisaram as relações desse comprometimento com a estrutura e com a cultura organizacional, explicitando-se os elementos de controle presentes no envolvimento sociológico, normativo e comportamental. Steil e Sanches (1998) observaram que as empresas têm aumentado a utilização de um SCG derivado da cultura organizacional. Para elas, os controles culturais são uma forma de "internalização dos valores organizacionais e das regras subliminareslsubjacentes a estes, resultando em uma gaiola de ferro cujas barras são praticamente invisíveis aos trabalhadores que esta encerra" (Steil; Sanches, 1998:11).

Embora a citação acima consista em uma afirmação bastante forte, a premissa central defendida pelas autoras é valida, pois, quando as expectativas dos indivíduos são contempladas na formulação dos objetivos empresariais, as pessoas passam a se auto regular e a estimular que os colegas alcancem as metas estabelecidas no planejamento e consigam as recompensas preestabelecidas. No contexto desta discussão, faz-se relevante ressaltar a possibilidade de utilizar o controle cultural para estimular a produção e o desenvolvimento do CI, pois o controle cultural permite estruturar uma abordagem integrativa que contemple, de maneira conjunta, essas duas 
tendências por utilizar o SCG para compartilhar o conhecimento através das pessoas e sistemas por meio da cultura organizacional, como demonstrado no modelo descrito na Figura 1. Farias et al. (2004) já haviam evidenciado o fato de que de nada adianta a empresa ter pessoas com destacados conhecimentos individuais, se elas trabalham isoladamente. Assim, compartilhar e transmitir conhecimentos dentro da empresa é uma atividade essencial para transformar o conhecimento pertencente aos funcionários em um ativo da empresa, na busca da consecução dos objetivos estratégicos corporativos. Esses autores argumentavam que, para isso, os ativos intelectuais estruturados como sistemas de informação, inteligência competitiva e de mercado, conhecimentos dos canais de mercado e foco gerencial são necessários para transformar o know-how individual em propriedade de um grupo.

Lima e Beinichis (2004) ressaltam, todavia, que o conhecimento, os processos de aprendizagem e a construção de competências relacionadas a esse processo são influenciados pelo meio em que ocorrem e pela forma de gestão utilizada pela empresa. Assim, a GC baseia-se em processos totalmente interativos e inerentes as pessoas, organizações e relacionamentos.

Para Fleury e Fleury (1997), aprendizagem é um processo de mudança resultante da prática ou experiência anterior, uma transformação no conteúdo da memória em longo prazo. A ideia central é que GC está permeada nos processos de aprendizagem organizacional, por meio de três processos que se inter-relacionam: aquisição e geração do conhecimento; disseminação, compartilhamento e transferência do conhecimento; e construção da memória coletiva de elaboração das competências necessárias à empresa.

Separando-se a aprendizagem em individual e organizacional, tem-se na primeira a ocorrência do processo de mudança de convicções que são codificadas como modelos mentais individuais. A aprendizagem organizacional, por sua vez, pode ser vista como a capacidade de uma organização em criar novo conhecimento, difundi-lo na organização como um todo e incorporá-lo a produtos, serviços e sistemas (Klein, 1998). Nesse sentido, considerando a intensificação do valor do conhecimento humano e da aprendizagem, de forma cada vez mais interativa e contínua dentro das empresas, torna-se importante que elas utilizem os processos de aprendizagem para criar e manter um diferencial competitivo sustentável resultando em incremento no valor do CI através da GC. Adicionalmente, a sugestão de alinhar os sistema de GC e controle cultural traz consigo a ideia das empresas como organismos capazes de acumular e produzir conhecimento, aprendendo com o ambiente e com suas próprias experiências. O’Dell e Grayson (1998) colocam a GC como uma estratégia estabelecida de forma consciente de usar o conhecimento certo, das pessoas certas, no 
Controle do Capital Intelectual: Um Modelo Aplicado à Gestão dos Ativos do Conhecimento

tempo certo e ajudar as pessoas a compartilhar e transformar a informação em ação, esforçando-se para melhorar o desempenho da empresa.

A informação é dinâmica e implica em tomada de decisão. Segundo Davenport e Prusak (1998) dados são definidos como um conjunto de fatos distintos e objetivos relativos a eventos que, quando trabalhados agregando-lhes valor, passam a constituir uma informação. Segundo Lima e Beinichis (2004), todavia, para esse processo de agregação de valor aconteça entre a informação e o conhecimento é necessário que haja tanto um trabalho de conexão e análise entre as informações, quanto um processo de socialização com outras pessoas para a validação do conhecimento. Esses autores ressaltam que o conhecimento possui algumas características próprias, como o fato de ser difundível, substituível, transportável e compartilhável. Hoss (2003) explica que a informação torna-se inútil sem o conhecimento do ser humano para aplicá-la produtivamente e que a transferência desse conhecimento pode ocorrer de duas maneiras: pela informação ou tradição. A informação é um tipo de comunicação utilizando a linguagem para articular alguns conceitos, na tentativa de transferi-los a outras pessoas - indicada para transmitir o conhecimento explícito. Já a transferência de conhecimento pela tradição se dá em conversas informais e de forma não estruturada.

Estudiosos têm indicado que a cultura organizacional é uma questão central na capacidade da empresa gerenciar seu conhecimento de maneira mais efetiva (Davenport; Klahr, 1998; Davenport; Delong; Beers, 1998; Delong, 1997). A cultura organizacional, ao acumular e transmitir informações e conhecimentos de e para os membros das empresas por meio das atividades de socialização, permite um intercâmbio de conhecimentos tácitos e explícitos. Além disso, o controle cultural ajuda a empresa a reter parte de tais informações e conhecimentos através da tradição que se estabelece entre os diferentes membros que trabalham em um determinado setor, segmento, nível hierárquico ou divisão organizacional. O controle cultural pode incorporar os aspectos que muitas empresas, baseadas no conhecimento, consideram importantes, como a avaliação de ativos do conhecimento formadores do capital intelectual, a melhoria dos processos internos e o aumento do aprendizado organizacional e do nível de satisfação dos consumidores com os produtos, serviços e processos da empresa.

O modelo de SGC ora proposto colabora para a implementação da estratégia da empresa, como preconizado por Anthony e Govindarajan (2002), e para a geração de valor. Tal sistema atua em uma abordagem multifocal: ao mesmo tempo em que se orienta para as variáveis exógenas buscando mapear as informações e mudanças advindas do mercado, se preocupa com as variáveis endógenas formadoras do conhecimento organizacional (para aprofundamentos, $c f$. Hoss, 2003). O 
SCG atua sobre os componentes do CI (capital humano, relacional e estrutural) na tentava de criar, armazenar, transmitir e sistematizar o conhecimento gerando novos produtos, serviços, sistemas e processos ou colaborando para aperfeiçoar os já existentes em um ciclo de melhoria contínua.

Enfim, o essencial, no contexto desta discussão, é perceber que, em linha com o pensamento de Kaplan e Norton (2001: 12), “as oportunidades de geração de valor estão migrando da gestão de ativos tangíveis para a gestão de estratégias baseadas no conhecimento, que exploram os ativos intangíveis da organização". Nesse sentido, as empresas cada vez mais carecem de usar o SCG para melhor compreender e valorizar: (1) o relacionamento com os clientes e fornecedores; (2) a criação de produtos e serviços inovadores; (3) o uso de bancos de dados e tecnologias de informação para melhorar os processos decisórios; (4) os mecanismos de motivação dos empregados e de estímulo a maior produtividade e criatividade; (5) a capacidade de gerar novas oportunidades, a partir das competências essências das corporações também chamadas de core competencies. E o mais importante, as empresas precisam do SCG para - para facilitar a integração dos cinco fatores anteriores com a estratégia empresarial - por meio do estabelecimento de um SCG eficiente e eficaz sobre o CI.

Desse modo, observa-se que o SCG tem o papel de promover a integração de todas as áreas, e todos os processos, sistemas e funções dentro da empresa para ajudá-la a cumprir sua missão e atingir seus objetivos estratégicos produzindo, desenvolvendo e gerenciando CI.

Enfim, como explicam Antunes e César (2007), os gestores, em linhas gerais, orientados pela missão da empresa, investem recursos físicos e financeiros nos recursos humanos da organização e propiciam as condições para o seu desenvolvimento. O recurso humano, por meio de suas habilidades e conhecimentos, gera o conhecimento organizacional que somado a outros ativos físicos e financeiros, materializa-se no CI da empresa afetando o seu desempenho e podendo gerarlhe um valor econômico a mais (consubstanciado em seu MVA).

\section{CONSIDERAÇÕES FINAIS}

A GC e o CI têm sido temas de grande relevância nas comunidades acadêmicas e no ambiente empresarial em função da capacidade que os ativos do conhecimento têm de multiplicar o valor das corporações. Cada vez mais as empresas dependem do CI por serem ativos estratégicos responsáveis pela geração e pela sustentação de vantagens competitivas e por constituírem o maior elemento patrimonial delas. A literatura evidencia que há atualmente vários esforços dirigidos para 
Controle do Capital Intelectual: Um Modelo Aplicado à Gestão dos Ativos do Conhecimento

seu dimensionamento, avaliação, gestão e controle. Ao lado dos esforços dos estudiosos em compreender o real valor desse tipo de ativos intangíveis, porém, há lacunas de pesquisa que precisam ser mais bem compreendidas derivantes das dificuldades encontradas pelas empresas em gerenciar, dimensionar e controlar esses ativos.

O SCG tem sido apontado na literatura como um dos fatores que colaboram para o sucesso das empresas por facilitar que os investimentos em CI sejam dimensionados e que os objetivos estratégicos estabelecidos para tais investimentos sejam alcançados. A literatura sugere que o estabelecimento de um SCG adequado sobre CI deve partir da hipótese de que os ativos e recursos básicos disponíveis para uma empresa - sejam eles pessoas, processos organizacionais e produtivos, tecnologias e insumos - somente são relevantes para a empresa se ela puder, de forma eficiente e eficaz, utilizar o conhecimento neles incorporado. Todavia, essa literatura não apresenta um meio que possibilite um efetivo controle sobre os ativos do conhecimento formadores do CI.

Assim, tendo-se essa premissa como base, buscou-se na pesquisa descrita neste artigo propor um modelo teórico-conceitual que colabore para o controle do CI e na GC. Nesse intuito, discutiu-se a concepção do SCG e analisaram-se estudos prévios que indicassem alternativas que permitissem a proposição do modelo em questão. Além disso, foram descritas e discutidas algumas abordagens de SCG, a influência da cultura organizacional no desenho desse sistema e o modo como ela facilita a disseminação e sistematização do conhecimento no âmbito das empresas, o efeito do controle cultural sobre a dimensão tácita e explícita de conhecimento, bem como os resultados de estudos anteriores que buscassem colaborar na avaliação, gestão e controle do CI.

Os resultados da análise realizada expandem o conhecimento do tema e ajudam a preencher a lacuna de pesquisa ora existente evidenciando que: (1) um desenho adequado do SCG pode contribuir para a externalização de parte do conhecimento tácito, transformando-o em explícito por meio da aculturação dos membros da empresa; (2) a cultura organizacional ajuda a disseminar e sistematizar o conhecimento na empresa; (3) o controle cultural pode colaborar para integrar o conhecimento, gerenciá-lo e transformá-lo em CI; e (4) o SCG pode colaborar para o processo de socialização do conhecimento individual e de institucionalização do conhecimento coletivo gerando valor para as empresas.

Dada a limitação de ser um modelo teórico-conceitual, como sugestão de futuras pesquisas, recomenda-se a investigação do funcionamento do modelo ora proposto em casos de empresas e posteriormente em estudos de larga escala, para permitir a confirmação em uma base empírica e o consequente refinamento do modelo. 
Do que foi apresentado, resta concluir que a cultura pode ser uma base para a construção de um modelo de controle sobre os ativos do conhecimento formadores do CI. Isso não quer dizer que esta seja uma alternativa fácil de ser executada ou que criar uma cultura que valorize as pessoas e promova a aprendizagem individual e organizacional e a inovação seja uma prática gerencial que poderá ser implantada em todo tipo de organizações (empresariais ou não). Todavia, esse modelo abre um caminho para a realização de novas pesquisas e para a observação empírica, bem como para o refinamento das práticas contemporâneas de gestão e dos sistemas de controle desta nova era que já se iniciou: a economia baseada no conhecimento.

\section{REFERÊNCIAS}

3M (2012). Blocos Post-it@. Disponível em: http://www.postit.com.br/wps/portal/3M/pt_BR/LAPost-it/Global/About/About/. Acessado em 02/09/2012.

Aboody, D.; Lev, B.. (1998). The Value-Relevance of Intangibles: The Case of Software Capitalization. Journal of Accounting Research, Supplement, p. 161-191. Acesso em: 04/07/2011.

Alvarenga Neto, R. C. D. de (2005). Gestão do conhecimento em organizações: proposta de mapeamento conceitual integrativo. $400 \mathrm{f}$. Tese (Doutorado em Ciência da Informação) ECI. UFMG.

Andrews, K. R. (1971). The Concept of Corporate Strategy. Dow Jones Irwin.

Anthony, R.N.; Govindarajan, V. (2002). Management Control Systems (9th ed.), Irwin / McGrawHill, Homewood.

Antunes, M. T. P.; Cesar, A. M. R. (2007). Gestão estratégica de pessoas: a interação entre as áreas de recursos humanos e controladoria. Anais da 5th Iberoamerican Academy of Management Conference. Santo Domingo, Dominican Republic.

Barbosa, J. G.; Gomes, J. S. (2002). Um estudo exploratório do controle gerencial de ativos e recursos intangíveis (capital intelectual) em empresas brasileiras. Revista de Administração Contemporânea, v. 6, n 2, p. 29-48, maio/ago. 
Controle do Capital Intelectual: Um Modelo Aplicado à Gestão dos Ativos do Conhecimento

Barros, B. T. (Org.) (2003). Fusões e aquisições no Brasil: entendendo as razões dos sucessos e fracassos. São Paulo, Atlas. Cap. 1.

Barth, M.; Clinch, G. (1998). Revalued Financial, tangible and intangible assets: Associations with share prices and non-market-based value estimates. Journal of Accounting Research, Vol. 36, Supplement, p. 199-233.

Behr, R. R.; Nascimento, S. P. (2008). A gestão do conhecimento como técnica de controle: uma abordagem crítica da conversão do conhecimento tácito em explícito. Cadernos EBAPE - FGV, vol $1, \mathrm{n}^{\mathrm{o}} 1$, março.

Boiral, O. (2002). Tacit Knowledge and Environmental Management. Long Range Planning, Vol.35, 291-317.

Brooking, A. (1996). Intellectual Capital. International Thomson Business Press. Thomson Learning Europe.

Calori, R.; Lubatikin, M.; Very, P. (1994). Control mechanisms in cross-border acquisitions: an international comparison. Special Issue on Cross-National Organizations Culture. European Group for Organizational Studies.

Cañibano, L.; Garcia-Ayuso, M.; Sanchez, P. (1999). La relevancia de los intangibles para la valoración y la gestión de las empresas: revisión de la literatura. Revista Española de Financiación y Contabilidad, nº 100, págs.17-88.

Cassel, C. M.; Hackl, P. (2000). On measurement of intangible assets: a study of robustness of partial least squares. Total Quality Management, Sep, Vol. 11 Issue 7, pS897, 11p.

Catelli, A. (Organizador) (1999). Controladoria - Uma Abordagem da Gestão Econômica. Ed. Atlas.

Choo, C. W.; Alvarenga Neto R. C. D.. (2010). Beyond the ba: managing enabling contexts in knowledge organizations. Journal of Knowledge Management. Volume: 14. N. 4 2010, pp. 592610. 2010.

Collins, Jim; Porras, Jerry I. (1994). Built to Last - Successful Habits of Visionary Companies. New York: Harperbusiness.

Cooper, D. R. e Schindler, P. S. (2003) Métodos de Pesquisa em Administração, $7^{\mathrm{a}}$ Edição, Porto. Alegre, Bookman.

Davenport, T. H.; Prusak, L. (1998). Conhecimento empresarial: como as organizações gerenciam seu capital Intelectual. Rio de Janeiro: Campus. 
Ricardo Vinícius Dias Jordão, Jorge Luís Pedreira Murteira Marques Casas Novas, Antônio Artur de Souza \& Jorge Tadeu de Ramos Neves

Davenport, T., Delong, D.; Beers, M. (1998). Successful Knowledge Management Projects. Sloan Management Review 39 (Winter): 43-57.

Davenport, T., P. Klahr. (1998). Managing Customer Support Knowledge. California Management Review, 40(3): 195-208.

Delong, D. (1997). Building The Knowledge-Based Organization: How Culture Drives Knowledge Behaviors. Working Paper, Ernst \& Young's Center For Business Innovation. Boston.

Deng, Z. B.; Lev F. N. (1999). Science \& Technology as Predictors of Stock Performance. Financial Analysts Journal, May/June, p. 20-32.

Edvinsson, L.; Malone, M. (1997). Intellectual Capital. Realizing your company's true value by finding its hidden brainpower. Harperbusiness, New York.

Farias, F. S. O.; Farias, I. Q.; Ponte, V. M. R. (2004). Gerenciamento do Capital Intelectual: um estudo em empresas do setor têxtil cearense. XXVIII Encontro da Associação Nacional dos Programas de Pós-Graduação em Administração (ENANPAD). 2004, Curitiba. Anais ... Curitiba.

Fleury, A.; Fleury, M. T. L. (1997). Aprendizagem e inovação organizacional: as experiências de Japão, Coréia e Brasil. São Paulo: Atlas, 1997.

George, A.; Bennett, G. (2005). Case studies and theory development in the social sciences. Cambridge, Massachussetts: MIT Press.

Gomes, J. S., Salas, J. A. (1997). Controle de gestão: uma abordagem contextual e organizacional. Textos e casos. São Paulo, Atlas.

Gomes, J. S.; Matos, F. F. J.; Rosa, W. C. C.; Palmeiro, M. A.; Netto, L. J. G.. (2000). Management control in the internacionalized firm: the case of Praxair Inc. Disponível em: http://www.estacio.br/revistamade

Granlund, M. (2003). Management accounting systems integration in corporate mergers: a case study. Accounting, Auditing and Accountability Journal, vol. 16, n. . 2, p. 208 a 243.

Grant, R. (1996). Toward a knowledge based theory of the firm. Strategic Management Journal, 17, 109-122. 50. Winter 1996.

Hofstede, G. (1982). Culture's consequences: comparing values, behaviors, institutions, and organizations. 1.ed. Londres: Sage Publications. 
Hofstede, G.H. (1978). The poverty of management control philosophy. Academy of Management Review.

Hoss, Osni. (2003). Modelo de avaliação de ativos intangíveis para instituições de ensino superior privado. UFSC, Santa Catarina, PR.

Johnson, H. T.; Kaplan, R. S.(1987). Relevance Lost: The Rise and Fall of Management Accounting, Harvard Business School Press.

Joia, L. A. (2000). Measuring intangible corporate assets: linking business strategy with intellectual capital. Journal of Intellectual Capital, pp. 68-84.

Jordão, R. V. D. (2009). Mudanças no sistema de controle gerencial na Extrativa Metalquímica S.A.: uma experiência brasileira de aquisição. Dissertação. Mestrado em Contabilidade e Controladoria, Faculdade de Ciências Econômicas da UFMG.

Jordão, R. V. D. . (2011). Knowledge management practices in micro and small enterprises of the Brazilian coffee industry organized in cooperative networks. In: XIII Seminário Luso-Espanhol de Economia Empresarial, Évora (Portugal).

Jordão, R. V. D. ; Novas, J. C. (2013) . A Study on the Use of the Balanced Scorecard for Strategy Implementation in a Large Brazilian Mixed Economy Company. In: The 2nd International Conference of Information and Communication Technologies, Zilina (Slovakia).

Jordão, R. V. D. ; Colauto, R. D. . Governança corporativa e evidenciação voluntária de ativos intangíveis: um estudo empírico nos setores de telecomunicações e de utilidade pública. CAP Accounting and Management (UFSC), v. 6, p. 124-138, 2012.

Jordão, R. V. D.; Souza, A. A. (2011). Organizational Culture and Post-acquisition Changes in Management Control Systems: An analysis of a successful Brazilian case. In: BALAS Conference, 2011, Santiago. Value Creation through Innovation: Latin America's Unavoidable Challenge.

Kakabadse, N. K.; Kakabadse, A.; Kouzmin, A. (2003). Reviewing the knowledge management literature: towards a taxonomy. Journal of Knowledge Management, v. 7, n. 4, p. 75-91.

Kaplan, R. S.; Norton, D. P. (2001). Organização orientada para a estratégia. Rio de Janeiro. Campus.

Klein, David A. (1998). A gestão estratégica do capital intelectual: recursos para economia baseada em conhecimento. Rio de Janeiro: Quallitymark.

Kristen, E.; Gregory W. (1999). Intangible assets and stocks prices in the pre-SEC Era. Journal of Accounting Research, Vol.37 Supplement 1999, p. 17-44. 
Ricardo Vinícius Dias Jordão, Jorge Luís Pedreira Murteira Marques Casas Novas, Antônio Artur de Souza \& Jorge Tadeu de Ramos Neves

Kumar, T. K. (2005). Disclosure norms for intangible assets: suggestions for improving the valuation of intangibles. IIMB Management Review, vol. 17, p.71-78, Mar.

Larsson, R.; Lubatkin, M. (2001). Achieving acculturation in mergers and acquisitions: an international case survey. Human Relations, vol. 54, p. 1573 a 1607.

Lev, B. (1999). R\&D and Capital Markets. Journal of Applied Corporate Finance, p. 21-35, spring.

Lima, M. L. S. C.; Beinichis, L. (2004). Avaliação de elementos da Gestão do Conhecimento em uma empresa prestadora de serviço: caso CASSI. XXIV Encontro Nac. de Eng. de Produção Florianópolis, SC, Brasil, 03 a 05 de nov.

Luthy, D. H. (1998). Intellectual capital and its measurement. APIRA. Disponível em: www3.bus.osaka-cu.ac.jp/apira98/archives/pdfs/25.pdf

Martins, E. (1972). Contribuição à avaliação do ativo intangível. 1972.109 f. Tese (Doutorado em Contabilidade e Controladoria). Curso de Pós-graduação em Contabilidade e Controladoria, FEA, USP, São Paulo.

Mendes, D. A.P.; Silva, C. E.V; Silva, J.A.; Gomes, J.S. (2002). Controle Gerencial em Empresas Brasileiras Internacionalizadas: O Caso do Bob’s. XXVI Encontro Nacional da Associação Nacional dos Programas de Pós-graduação em Administração (ENANPAD). Salvador, BA, 2002. Anais... ENANPAD. Salvador, BA.

Montgomery,C.; Porter, M. E. (1998). Estratégia: a busca da vantagem competitiva. Rio de Janeiro : Campus.

Mouritsen, J.; Bukh, P.N.; H.T. Larsen, M.R. Johansen. (2002). Developing and managing knowledge through intellectual capital statements. Journal of Intellectual Capital. Vol. 3 Iss: 1, pp. $10-29.2002$.

Mouritsen, J.; M.R. Johansen, H.T. Larsen, P.N.. Bukh. (2001). Reading an intellectual capital statement: Describing and prescribing knowledge management strategies. Journal of Intellectual Capital, Vol. 2 Iss: 4, pp.359-383.

Nonaka, I. (1991). The Knowledge-Creating Company. Harvard Business Review, Vol.69, N. ${ }^{6}$, 96104.

Nonaka, I.; Takeuchi, H. (1997). Criação do conhecimento na empresa. Rio de Janeiro. Ed. Campus. 
Novas, J. C., Sousa, A.; Alves, M. C. (2012). On the Relations Between Management Accounting Systems and Intellectual Capital. Evidence for Portuguese Companies, CEFAGE-UE Working Paper 2012/13.

Novas, J.C. (2008). A Contabilidade de Gestão e o Capital Intelectual: Elementos Integradores e Contributos para uma Gestão Estratégica das Organizações, Ph.D. Thesis, Universidade de Évora, Portugal.

O'dell, C.; Grayson, C. (1998). If Only We Knew What We Know: Identification And Transfer Of Internal Best Practices. California Management Review 40 (3).

Organização para a Cooperação e Desenvolvimento Econômico (OECD) (2010). Measuring Innovation: A New Perspective, OECD Publishing.

Ortiz, M.A.A. (2006). Intellectual capital (intangible assets) valuation considering the context. Journal of Business and Economics Research. disponível em: www.uas.mx/negocios/publicaciones/international_papers.htm - Acesso: 11/05/2008.

Perez, M. M.; Famá, R. (2006). Ativos intangíveis e o desempenho empresarial. Revista Contabilidade \& Finanças, v. 1, p. 7-17.

Prahalad, C.K., Hamel, G. (1990). The core competence of the corporation. Harvard Business Review, Boston, v. 68, n. 3, p. 79 - 91, maio/jun.

Queiroz, A. B., Fuertes C.; Serrano C. C. (2001). El capital intelectual en el sector público. II Congreso de la Asociación Española de Contabilidad Directiva, Leon. 2001.

Rappaport, A. (1998). Creating Shareholder Value. New York, The Free Press, 2 ed.

Richardson, R. J. (1999). Pesquisa social: métodos e técnicas. 3. ed. São Paulo: Atlas.

Rodrigues, S. B.; Barros, B. T. (2001). Compreendendo a dimensão cultural. Cap. 6. 3. In: Barros, B. T. (Org.). Fusões, aquisições e parcerias. São Paulo, Atlas.

Roos, J. (1996). Intellectual Capital - What You Can Measure You can Manage. IMD Perspectives for Managers, Vol. 26, No. 10, November.

Roos, J.; Roos, G.; Dragonetti, N.C.y Edvinsson, L. (1997). Intellectual Capital: navigating in the new business landscape, McMillan Business, London, 1997.

Rossoni, C. F. (2010). Balanced Scorecard mediado pela gestão do conhecimento: modelo de uso para micro e pequenas empresas. Revista da Micro e Pequena Empresa, Campo Limpo Paulista, v.3, n.3, p.20-35. 
Ricardo Vinícius Dias Jordão, Jorge Luís Pedreira Murteira Marques Casas Novas, Antônio Artur de Souza \& Jorge Tadeu de Ramos Neves

Silva, J. S. (2008). O Capital Intelectual nos Sistemas de Planejamento e Controle em empresas internacionalizadas: um estudo de caso. Dissertação de Mestrado em Ciências Contábeis. UERJ. Rio de Janeiro, RJ.

Silva, S. M. L. R. (2004). Aplicação de ferramenta de medição de capital intelectual em uma empresa industrial. Dissertação - (Mestrado em Administração). MPA, PUC-Minas e Fundação Dom Cabral, Belo Horizonte, MG.

Steil, A. V. ; Sanches, E. N. (1998). Comprometimento organizacional como uma estratégia de controle. In: XXII Encontro Nacional da Associação Nacional dos Programas de Pós-graduação em Administração (ENANPAD). Foz do Iguaçú, PR. Anais ... ENANPAD.

Stewart, Thomas A. (1998). Capital intelectual: a nova vantagem competitiva das empresas. 2. ed., Rio de Janeiro: Editora Campus.

Stolowy H. Y; Jeny A. (1999). How accounting standards approach and classify intangibles - an international survey. 22nd Annual Congress of the European Accounting Association, Bordeaux, France.

Sveiby, K. E. (1989). The invisible balance sheet: key indicators for accounting, control and valuation of know how companies. Disponível em <http://www.sveiby.com/aticles/denosynl.htm>. Acesso em 31/03/2008.

Sveiby, K. E. (1997). The new organizational wealth. San Francisco: Berret-Koehler Publishers.

Tinoco, J.E.P. (1996). Contribuição ao estudo da contabilidade estratégica de recursos humanos. Tese (Doutorado em Controladoria e Contabilidade) - FEA, Universidade de São Paulo, São Paulo.

\section{Recebido: 07/01/2013}

Aprovado: 21/02/2013 